\title{
BMJ Open Play interventions for paediatric patients in hospital: a scoping review
}

\author{
Line Klingen Gjærde (D) ," Jane Hybschmann, ${ }^{1}$ Daniel Dybdal, ${ }^{1}$ \\ Martha Krogh Topperzer, ${ }^{1}$ Morten Arnborg Schrøder, ${ }^{1}$ Jenny Louise Gibson, ${ }^{2}$ \\ Paul Ramchandani, ${ }^{2}$ Elisabeth Ida Ginsberg, ${ }^{1}$ Bent Ottesen, ${ }^{1,3}$ \\ Thomas Leth Frandsen, ${ }^{1}$ Jette Led Sørensen ${ }^{1,3}$
}

To cite: Gjærde LK, Hybschmann J, Dybdal D, et al. Play interventions for paediatric patients in hospital: a scoping review. BMJ Open 2021;11:e051957. doi:10.1136/ bmjopen-2021-051957

- Prepublication history and additional supplemental material for this paper are available online. To view these files, please visit the journal online. To view these files, please visit the journal online (http://dx.doi. org/10.1136/bmjopen-2021051957).

Received 03 April 2021 Accepted 13 July 2021

Check for updates

(C) Author(s) (or their employer(s)) 2021. Re-use permitted under CC BY-NC. No commercial re-use. See rights and permissions. Published by BMJ.

${ }^{1}$ Children's Hospital Copenhagen and Juliane Marie Centre, Rigshospitalet, Copenhagen, Denmark

${ }^{2}$ Centre for Research on Play in Education, Development \& Learning, Faculty of Education

Cambridge University,

Cambridge, UK

${ }^{3}$ Department of Clinical

Medicine, Faculty of Health and Medical Sciences, University of Copenhagen, Copenhagen, Denmark

\section{Correspondence to} Dr Line Klingen Gjærde; line.klingen.gjaerde.01@ regionh.dk

\section{ABSTRACT}

Objective Play is a non-invasive, safe and inexpensive intervention that can help paediatric patients and their families manage difficult aspects of being ill or hospitalised. Although play has existed in hospitals for decades, research on hospital play interventions is scarce. This review aimed to categorise and synthesise the last 20 years of research on hospital play interventions.

Design Scoping review.

Data sources PubMed, CINAHL, CENTRAL, ERIC and PsycINF0 (1 January 2000- 9 September 2020).

Study selection and data extraction We systematically searched for original peer-reviewed articles, written in English, on hospital play interventions in paediatric patients (0-18 years) in non-psychiatric settings. Two reviewers independently screened titles and abstracts, reviewed full text of relevant articles and extracted data. We thematically synthesised the data from the included studies, and a descriptive analysis, based on a developed framework, is presented.

Results of the 297 included articles, $78 \%$ came from high-income countries and $56 \%$ were published within the last 5 years. Play interventions were carried out across all ages by various healthcare professionals. Play interventions served different roles within four clinical contexts: A) procedures and diagnostic tests, B) patient education, C) treatment and recovery and D) adaptation. Across these contexts, play interventions were generally facilitated and purpose-oriented and had positive reported effects on pain, stress, and anxiety.

Conclusions Play in hospitals is an emerging interdisciplinary research area with a significant potential benefit for child and family health. Future research should further describe principles for play in hospitals. High-quality studies investigating short-term and longterm effects are needed to guide when and how to best integrate play in hospitals.

\section{INTRODUCTION}

Play, long viewed as a means for children to cope with the challenges of hospitalisation, ${ }^{1}$ is a way to reduce and prevent stress and anxiety in children. ${ }^{2-4}$ Play is recognisable, safe and can be used to communicate complex information in an age-appropriate manner. ${ }^{2}$ Furthermore, play is essential for healthy development, and adopting play

\section{Strengths and limitations of this study}

- This review provides a comprehensive overview of 297 systematically collected original articles on play interventions in hospitals.

- The scoping review methodology allowed for assessing a wide variety of articles and identifying significant gaps in the literature.

- Drawing conclusions about implementation of play interventions remains difficult, as the existing literature is heterogenous with great variation in participants, comparator groups, study designs and outcomes.

- Grey literature, articles not written in English and unpublished studies were excluded.

interventions into the treatment and care of paediatric patients may reduce developmental regression. ${ }^{2}$

The WHO's standards of children's rights in hospital include the right to play. Recently, the WHO recommended that all doctors and nurses utilise play within treatment and care and that hospitals promote research on using play. ${ }^{5}$

Rapid turnover of hospitalised children, with few staying for longer periods, limits opportunities for playful relationships and comfortable familiarity with hospital playrooms. ${ }^{6}$ Consequently, hospital play interventions are often individualised and treatment-oriented. In some countries play facilitated by specially trained staff for selected patients, rather than a normal, everyday activity. ${ }^{67}$ Moreover, hospital resources, children's health status and treatment needs, expectations about illness and health behaviour influence the implementation of play interventions. ${ }^{268}$ Attitudes towards children's integrity and adult participation in the child's play and the acceptance of playing with particular toys also affect the practices of play in hospitals. ${ }^{9}$

While many different traditions and practices exist in hospitals, most countries lack 
formalised programmes on the use of play interventions. This might stem from a lack of knowledge on when, where and how to best practice play in the treatment and care of paediatric patients. Uniform implementation may be further challenged by continually changing conditions in healthcare.

Previous meta-analyses ${ }^{10}{ }^{11}$ and systematic reviews ${ }^{12-21}$ have examined specific areas of play in hospitals, or specific play solutions for paediatric patients, but reviews on the general use of play in hospitals are limited. Existing reviews are further impaired by non-systematic literature searches and few included studies. ${ }^{22} 23$ Therefore, this scoping review aims to categorise and synthesise the scientific literature on the use of hospital play interventions in the last 20 years to potentially inform, guide and encourage future efforts in using and evaluating play interventions in the care of paediatric patients.

\section{METHODS}

\section{Search strategy and selection criteria}

We conducted a scoping review, in accordance with Joanna Briggs Institute guidelines ${ }^{24}$ and the underlying framework by Arksey and O'Malley. ${ }^{25}$ This method is particularly relevant for presenting a broad overview of existing literature within an emerging scientific field, enabling rapid identification and mapping of key concepts and knowledge gaps. ${ }^{25}$ We searched PubMed, CINAHL, CENTRAL, ERIC and PsycINFO for entries from 1 January 2000 to 7 June 2019 and updated it on 9 September 2020. Our search strategy followed the Peer Review of Electronic Search Strategies Statement ${ }^{26}$ and was developed in collaboration with two information specialists. The full search terms are listed in online supplemental table 1 . Our review protocol can be accessed on request.

We searched for peer-reviewed original studies available in English on play interventions within a hospital context in relation to various health-related and treatment-related outcomes among children and adolescents aged 0-18 years. Because formal consensus on the definition of play is lacking, ${ }^{28}$ we included any intervention using a playful approach actively involving patients, but we excluded creative arts therapies such as music therapy. Play interventions may depend on age and developmental status. However, evidence-based age-specific subdivisions of play interventions are lacking in the existing literature. Therefore, we chose to search the broad paediatric population and subsequently describe the influence of age on choice and effect of the play interventions.

Hospital context was defined as somatic inpatient and outpatient settings and included rehabilitation centres and home treatment preceded by and/or followed up in an inpatient or outpatient setting. We excluded reviews, case reports, case series, studies with $<5$ participants and studies with a mean participant age $>18$ years or if $<50 \%$ of participants were $0-18$ years.

We imported search results into EndNote (V.X8, Clarivate Analytics, Philadelphia, Pennsylvania, USA) removing duplicates. Two independent reviewers (LKG, DD or JH) screened titles and abstracts using Rayyan systematic review software. ${ }^{27}$ Final eligibility was assessed by reviewing the full text.

\section{Data extraction}

We developed a coding framework using a thematic synthesis approach inspired by Thomas and Harden. ${ }^{28}$ Two reviewers (LKG, JH) extracted data on key study characteristics (publication year, country of origin, design, title, aim, number of participants, age, intervention, outcomes, tools for assessment, profession involved, disease category, procedure and type of play). To get an overview of which kind of resource settings the play intervention research originated from, we grouped the countries according to income using the World Bank's definition. ${ }^{29}$ Uncertainties in data extraction were discussed with MS, MKT and JLS.

Based on extracted data, LKG and JH identified roles of the play interventions in included studies which led to the development of a broad coding framework. These thematic categories were discussed with the multidisciplinary coauthor group, comprising medical doctors with various specialties and competencies in medical education and management, an academic nurse and sociologist, a psychologist and researchers within public health and cultural studies. LKG and JH conducted a final coding based on the clinical contexts in which play interventions served different roles. Disagreements were solved in consultation with MKT and/or JLS. Descriptive statistics were analysed using Excel (V.2016, Microsoft, Redmond, Washington, DC, USA) and R (V.4.0.1, R Foundation for Statistical Computing, Vienna, Austria). Our report follows the Preferred Reporting Items for Systematic reviews and Meta-Analyses extension for Scoping Reviews checklist. ${ }^{30} 31$ As critical appraisal, which is optional in the scoping methodology, we summarised key characteristics such as study design, randomisation approach, number of centres involved, population size and comparator group to give an overall impression of the risks of bias. Within each of the thematic categories of the framework, we describe the reported general effects of the play interventions.

\section{Patient and public involvement}

No patients were involved in carrying out this scoping review.

\section{RESULTS}

Of 3711 articles, 297 were included in the final review (figure 1). Detailed information on the included studies can be found in online supplemental tables 2 and 3 . Articles originated from high-income countries (78\%), particularly the USA, or middle-income countries (22\%) (figure 2A). Since 2000, the number of articles published annually has increased steadily (figure $2 \mathrm{~B}$ ). 


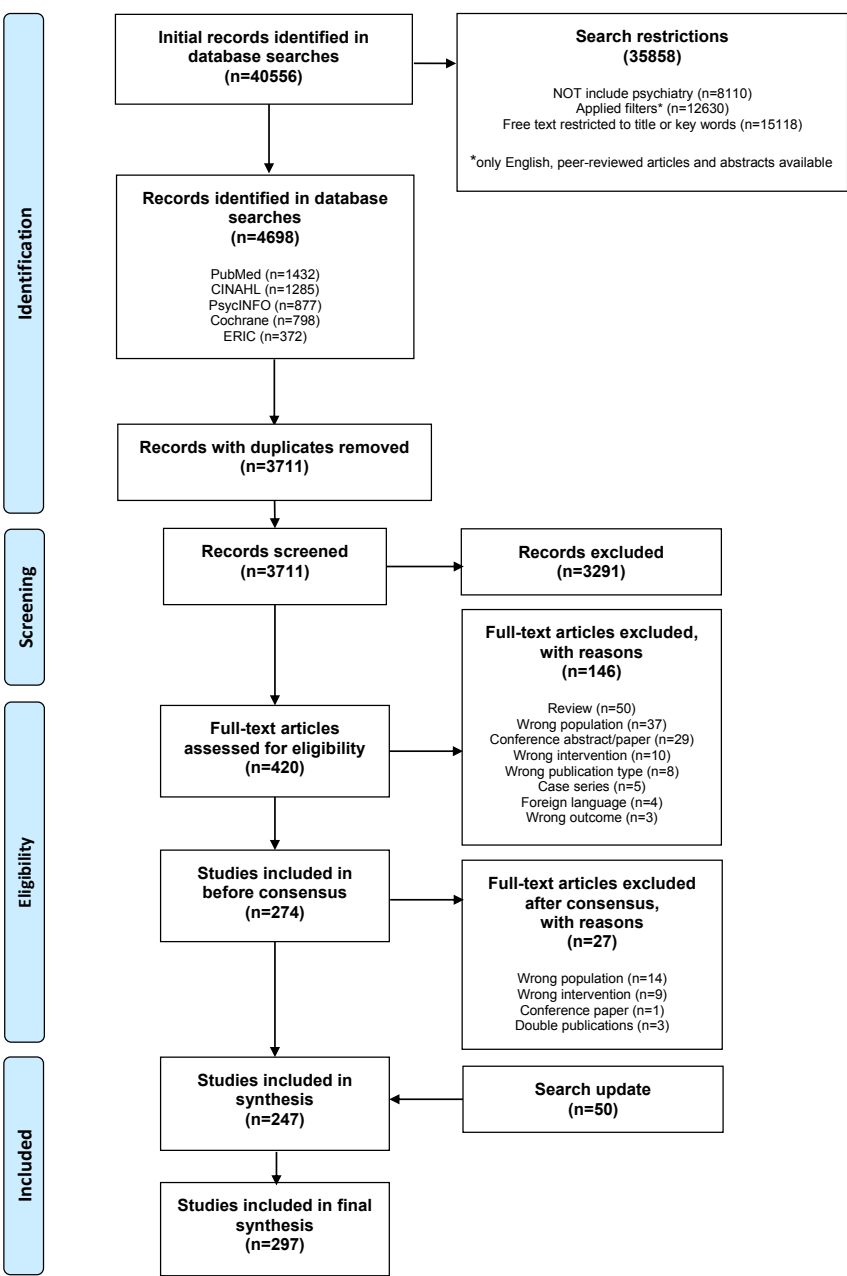

Figure 1 Preferred Reporting Items for Systematic Reviews and Meta-Analyses flow diagram of the study selection process.

The studies were generally small, with less than 25 participants in nearly one-third of them (figure 2C). Play interventions were used for all patients aged $0-18$ years (figure 2D). We were unable to report age and developmental status-specific findings, because stratification based on these factors was limited. The interventions were mostly directed towards individual patients $(94 \%)$ as opposed to groups $(6 \%)$. Used within 13 disease categories (table 1), hospital play interventions were carried out by various professions (table 2 ).

\section{Role of play within clinical contexts}

Play interventions served different roles within four clinical contexts: (A) procedures and diagnostic tests, (B) patient education, $(\mathrm{C})$ treatment and recovery and (D) adaptation (figure 3). Each context is summarised later, including context-specific study characteristics and examples (final coding agreement was 95\%, 281/297 articles).

\section{A) Play in procedures and diagnostic tests}

In this context, play was used to either (1) distract the patient during a procedure (74 articles) or (2) prepare or support the patient before or during a procedure (55

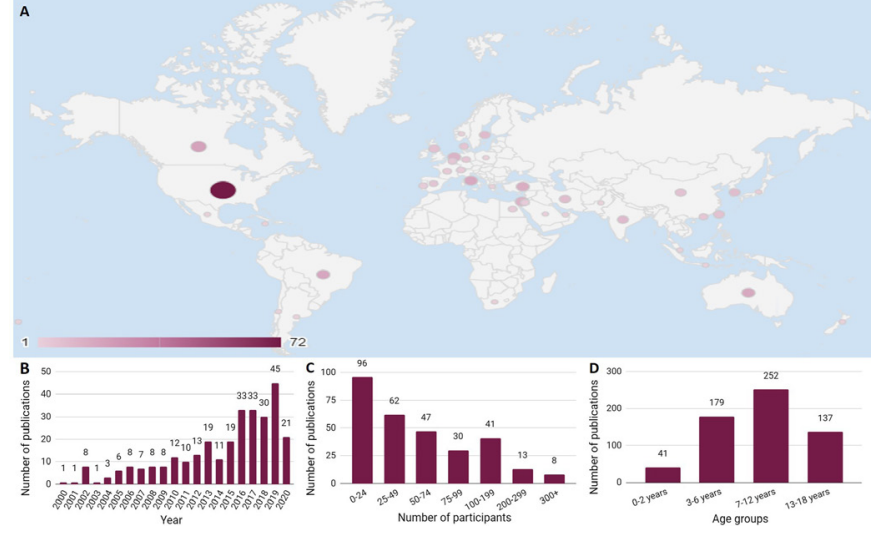

Figure 2 Summary characteristics of included studies. (A) Number of publications by county. (B) Number of publications per year. ${ }^{a}$ (C) Number of participants. (D) Age range of participants. Studies that include one or more age groups are counted accordingly. ${ }^{\text {a } 2020}$ publications included up to 9 September 2020.

articles). The primary purpose was to reduce anxiety, pain or distress (figure 4).

\section{Distraction}

Play as a distraction was used for needle-related or other distressing procedures (table 3). Self-directed distractors (eg, handheld digital games, virtual reality (VR) games or toys such as kaleidoscopes) were more frequently used than facilitated distractions (where a parent, healthcare professional, or hospital clown blew soap bubbles or played with toys).

Playful distraction generally had positive effects, but when compared with non-play distractions, the effect was often similar. ${ }^{32-34}$ Despite the frequent use of digital play distractors, their superiority over non-digital distractors was not evident, which a recent meta-analysis also concluded..$^{10}$ Furthermore, the comparator group and the definition of standard care varied greatly between the studies (table 3). Only one study examined whether the effect of distraction persisted in recurring procedures. ${ }^{35}$

\section{Preparation and support}

Playful preparation and support were used for surgeries or complex diagnostic tests, for example, imaging (table 3). This included digital media as part of structured preparational play (eg, VR tours in the operating room or online games) and creating a pretend journey with the child. Support before or during a procedure was used with younger patients, often by a hospital clown, through various playful approaches to help and encourage them by mirroring feelings or cheering them up.

Mostly positive effects were found. Three studies reported no effect of playful preparation on preoperative anxiety. ${ }^{36-38}$ Despite generally large sample sizes, the heterogeneity of the studies limited comparisons (table 3), which is consistent with findings from prior reviews. ${ }^{12-17}$ 


\begin{tabular}{|c|c|c|c|c|c|}
\hline Disease groups ${ }^{\star}$ & $\mathrm{N}(\%)$ & & Disease groups* & $\mathbf{N}(\%)$ & \\
\hline Cardiological diseases & $4(1.3)$ & & Unspecified respiratory & & $2(18.2)$ \\
\hline Congenital & & $3(75.0)$ & diseases & & \\
\hline Unspecified & & $1(25.0)$ & Rheumatological diseases & $2(0.7)$ & \\
\hline Emergency medicine/care & $14(4.7)$ & & Juvenile idiopathic arthritis & & $2(100)$ \\
\hline Musculo-skeletal trauma & & $1(7.1)$ & Surgical diseases & $69(23.2)$ & \\
\hline Laceration repair & & $2(14.3)$ & Appendicitis & & $1(1.4)$ \\
\hline Unspecified & & $11(78.6)$ & Burns & & $18(26.1)$ \\
\hline Endocrinological diseases & $16(5.4)$ & & Umbilical or inguinal hernia & & $1(1.4)$ \\
\hline Type 1 diabetes & & $6(37.5)$ & Chronic wounds & & $1(1.4)$ \\
\hline Type 1 and 2 diabetes & & $1(6.3)$ & Lower limb amputation & & $1(1.4)$ \\
\hline Overweight/obesity† & & $9(56.3)$ & Meatal stenosis & & $1(1.4)$ \\
\hline Gastroenterological diseases & $2(0.7)$ & & Tooth extraction & & $2(2.9)$ \\
\hline Inflammatory bowel & & $1(50.0)$ & Transplant receivers & & $1(1.4)$ \\
\hline Unspecified & & $1(50.0)$ & Various specified surgical & & $16(23.2)$ \\
\hline Intensive care & $1(0.3)$ & & diseases & & \\
\hline Unspecified & & $1(100.0)$ & Unspecified surgical diseases & & $27(39.1)$ \\
\hline Nephrological diseases & $2(0.7)$ & & Other & $6(2.1)$ & \\
\hline Daytime urinary incontinence & & $1(50.0)$ & Down's syndrome & & $1(16.7)$ \\
\hline Unspecified & & $1(50.0)$ & Immunisation & & $5(83.3)$ \\
\hline Neonatology & $8(2.7)$ & & $\begin{array}{l}\text { Various specified medical or } \\
\text { surgical diseases }\end{array}$ & $10(3.4)$ & \\
\hline Prematurity & & $8(100)$ & Unspecified & $30(10.1)$ & \\
\hline Neurological diseases & $67(22.6)$ & & Total & $297(100)$ & \\
\hline
\end{tabular}

\begin{tabular}{|c|c|c|}
\hline Acquired brain injury & & $2(3.0)$ \\
\hline Cerebral palsy & & $47(70.1)$ \\
\hline $\begin{array}{l}\text { Other neuromotor and } \\
\text { neuromuscular deficits } \neq\end{array}$ & & $12(17.9)$ \\
\hline Chronic headache & & $1(1.5)$ \\
\hline Muscular dystrophy & & $4(6.0)$ \\
\hline Epilepsy & & $1(1.5)$ \\
\hline $\begin{array}{l}\text { Oncological/haematological } \\
\text { diseases }\end{array}$ & $41(13.8)$ & \\
\hline $\begin{array}{l}\text { Central nervous system } \\
\text { tumour }\end{array}$ & & $6(14.6)$ \\
\hline Leukaemia & & $2(4.9)$ \\
\hline Osteosarcoma & & $1(2.4)$ \\
\hline Sickle cell disease & & $2(4.9)$ \\
\hline Various specified diseases§ & & $14(34.1)$ \\
\hline Unspecified cancers & & $16(39.0)$ \\
\hline Ophthalmological diseases & $14(4.7)$ & \\
\hline Amblyopia/strabismus & & $14(100)$ \\
\hline $\begin{array}{l}\text { Allergic and respiratory } \\
\text { diseases }\end{array}$ & $11(3.7)$ & \\
\hline Allergy & & $1(9.1)$ \\
\hline Asthma & & $4(36.4)$ \\
\hline Cystic fibrosis & & $4(36.4)$ \\
\hline
\end{tabular}

Continued

*Psychiatry literature was excluded during the selection process. †Two studies also included obesity in Prader Willi syndrome. łIncludes Erb's palsy, central gait disorders, congenital haemiplegia, degenerative ataxia, spina bifida, and other neuromotor and neuromuscular deficits that are unspecified in included studies.

§Mixed haematological and oncological diseases.

B) Play in patient education

In this context, play was used to teach patients about their disease and treatment (11 articles) to manage symptoms and promote medication adherence (figure 4 ).

\section{Knowledge, skills and attitudes on disease and treatment}

Play interventions were used to educate children as young as 5 years suffering from severe or chronic diseases eg, cancer, asthma or diabetes (table 3). Digital games were used in self-directed patient education. In one study, ${ }^{39}$ a robot was used to quiz the patients. ${ }^{39}$ Puppets were used to improvise real or fictitious situations to educate patients and facilitate a dialogue about disease management. ${ }^{4041}$

All but one intervention ${ }^{42}$ increased knowledge but affected symptoms to a lower degree. Two studies found that self-management awareness and the allure of being quizzed by a robot declined over time. ${ }^{39}{ }^{43}$ Despite the low number of studies using play in patient education, almost 
Table 2 Professions ${ }^{*}$ involved in the planning, execution and/or evaluation of the play intervention

\begin{tabular}{|c|c|c|}
\hline Profession & $\mathbf{N}(\%)$ & \\
\hline Clinical staff & $226(57.7)$ & \\
\hline Nurses (from various specialties, eg, oncology, anaesthetics (including students)) & & $102(26.0)$ \\
\hline $\begin{array}{l}\text { Medical doctors (including paediatricians, anaesthesiologists, ophthalmologists, } \\
\text { allergists, rheumatologists, radiologists) }\end{array}$ & & $55(14.0)$ \\
\hline Psychologists & & $17(4.3)$ \\
\hline Paediatric dentists & & $2(0.5)$ \\
\hline Unspecified health professionals (including research teams) & & $50(12.8)$ \\
\hline Creative or play professions & $42(12.5)$ & \\
\hline Hospital clowns & & $21(5.3)$ \\
\hline Child life specialists & & $17(4.3)$ \\
\hline Play specialists (including play therapists, play coordinators) & & $6(1.5)$ \\
\hline Music therapists & & $3(0.8)$ \\
\hline Game designers & & $2(0.5)$ \\
\hline Pet teams & & $2(0.5)$ \\
\hline Dance artists & & $1(0.3)$ \\
\hline Rehabilitation or training professions & $85(21.5)$ & \\
\hline Physiotherapists (including students and physical education teachers) & & $68(17.2)$ \\
\hline Occupational therapists (including students) & & $13(3.3)$ \\
\hline Sport instructors & & $4(1.1)$ \\
\hline Other professions & $24(6.1)$ & \\
\hline $\begin{array}{l}\text { Other health professionals (including dieticians, porters, hospital teachers, speech } \\
\text { therapists) }\end{array}$ & & $9(2.3)$ \\
\hline Teachers & & $3(0.8)$ \\
\hline Social workers & & $4(1.0)$ \\
\hline Not reported & $8(2.2)$ & \\
\hline Total & $395(100)$ & \\
\hline
\end{tabular}

*More than one profession can be involved in an intervention.

half of the included articles reported findings from large multicentre studies (table 3 ).

There was generally a lack of studies that conducted a long follow-up on interventions that both increase knowledge and improve symptoms, which prior reviews also noted. ${ }^{111819}$

\section{C) Play as treatment and recovery}

In this context, play interventions were used either (1) to replace or supplement medical or surgical treatment (24 articles) or (2) as rehabilitation or exercise (95 articles). The purpose of the studies varied substantially, reflecting the heterogeneity of studies within and between the two categories (figure 4).

\section{Medical or surgical treatment}

More than half of the studies used digital media, for example, video or tablet games, as a replacement for conventional patch treatment in children with amblyopia (table 3). Otherwise, VR, similar to that used to facilitate procedures, was used as a distraction to reduce acute pain or as a complementary treatment to inadequate pain management (eg, during sickle cell crisis). One study used a more advanced VR system employing biofeedback and positive images to treat chronic headache. ${ }^{44}$

The treatment interventions mainly had positive effects and could serve as an adjunct to standard treatment but were not necessarily better than conventional treatments.

\section{Rehabilitation or exercise training}

Play was used for rehabilitation in patients with chronic conditions such as cerebral palsy or in preterm children (table 3). Play was also used as an exercise for patients with, for example, obesity, cystic fibrosis or asthma. Digital games, the dominant types of play, were mainly investigated in small feasibility studies with no comparator groups.

The play interventions using digital media were generally feasible and safe, including complex VR games and robots. Play had the potential to increase adherence to programmes ${ }^{45} 46$ and could serve as efficient supplemental in-home training. ${ }^{47-49}$ Especially VR and video games showed promising results on strength and mobility, 


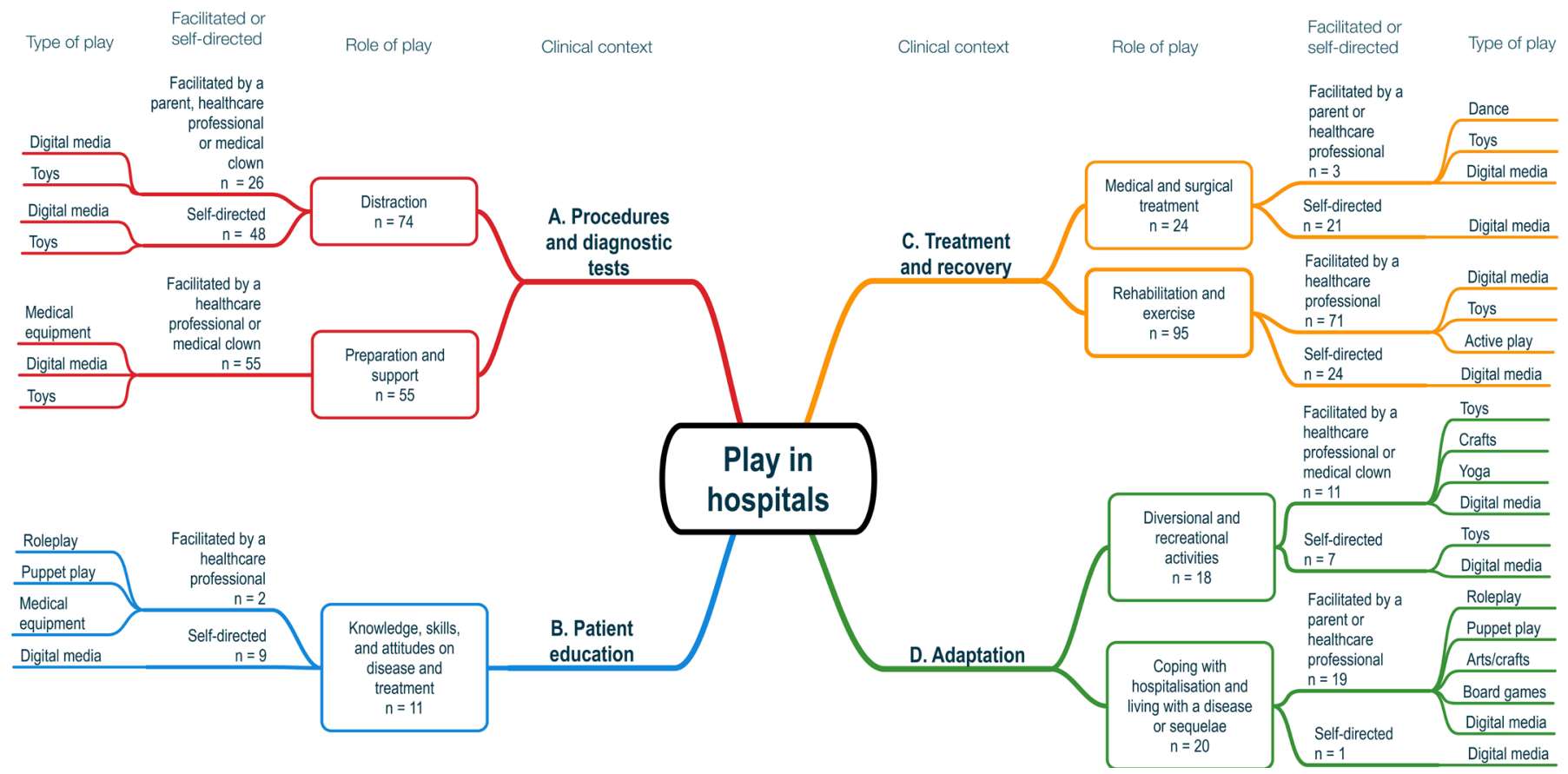

Figure 3 Conceptual model developed with a thematic approach mapping 'play in hospitals' by context, role of play, facilitated/self-directed and type of play.

which prior reviews also support. ${ }^{20} 21$ When compared with conventional therapy, digital solutions were often, but not always, ${ }^{50}$ better. Some studies also reported the risk of patients experiencing intervention fatigue. ${ }^{39} 4651$

Study periods were mostly short (2-8 weeks), limiting the investigation of long-term effects, with only one study reporting effects of an intervention after 12 months. ${ }^{47}$ Few disease groups were represented, potentially limiting applicability of the interventions to other disease groups. ${ }^{52}$

\section{D) Play as adaptation}

In this context, play interventions were characterised as (1) diversional or recreational activities (18 articles) or as (2) activities designed to help the child or adolescent cope with being hospitalised or ill (20 articles), often to reduce anxiety and stress or improve mood (figure 4).

\section{Diversional and recreational activities}

Most diversional or recreational play activities during hospitalisation occurred in patient rooms, playrooms, or waiting areas (table 3 ). There was predominantly unstructured play with toys and crafts, and play specialists, social robots, or hospital clowns visiting patient rooms.

Recreational or diversional play generally demonstrated positive effects. However, one study showed that stress was

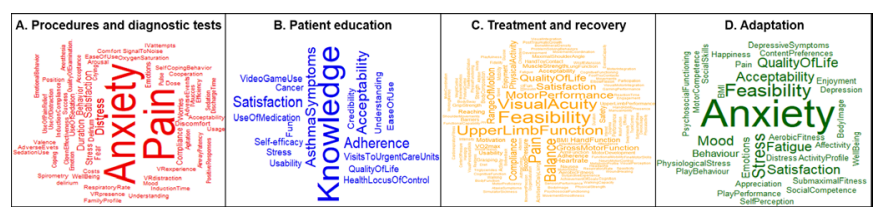

Figure 4 Word clouds on outcomes according to context of play. only reduced in patients $>7$ years,${ }^{53}$ while other studies reported that the effect of, for example, clown or social robot visits, waned over time. ${ }^{545}$ Moreover, play was less efficient in reducing anxiety than other therapies, such as music and pet therapy. ${ }^{56} 57$

No studies investigated the long-term effects of unstructured play during hospitalisation on, for example, quality of life or general childhood development.

\section{Coping with hospitalisation and living with a disease or sequalae}

Play was used to help patients to better cope with hospitalisation, disease or sequelae, especially in relation to cancer (table 3). Activities such as creative play, digital social media platforms, and board games allowed expression of feelings about being ill and hospitalised. Play involving physical activity followed by an evaluation by a healthcare professional was also seen as improving coping. Primarily carried out in groups, interventions were facilitated by a healthcare professional, whose importance was also highlighted when digital social media was involved.

One-third of the studies were qualitative but generally lacked a theoretical framework. Quality of life and improved social skills were sparsely studied, just as longterm follow-up on diversional or recreational play was absent.

\section{DISCUSSION}

We identified four clinical contexts where play had distinct roles: A) procedures and diagnostic tests, where play as distraction, preparation and support was used to alleviate pain, stress and anxiety; B) patient education, where play was used as age-appropriate communication 


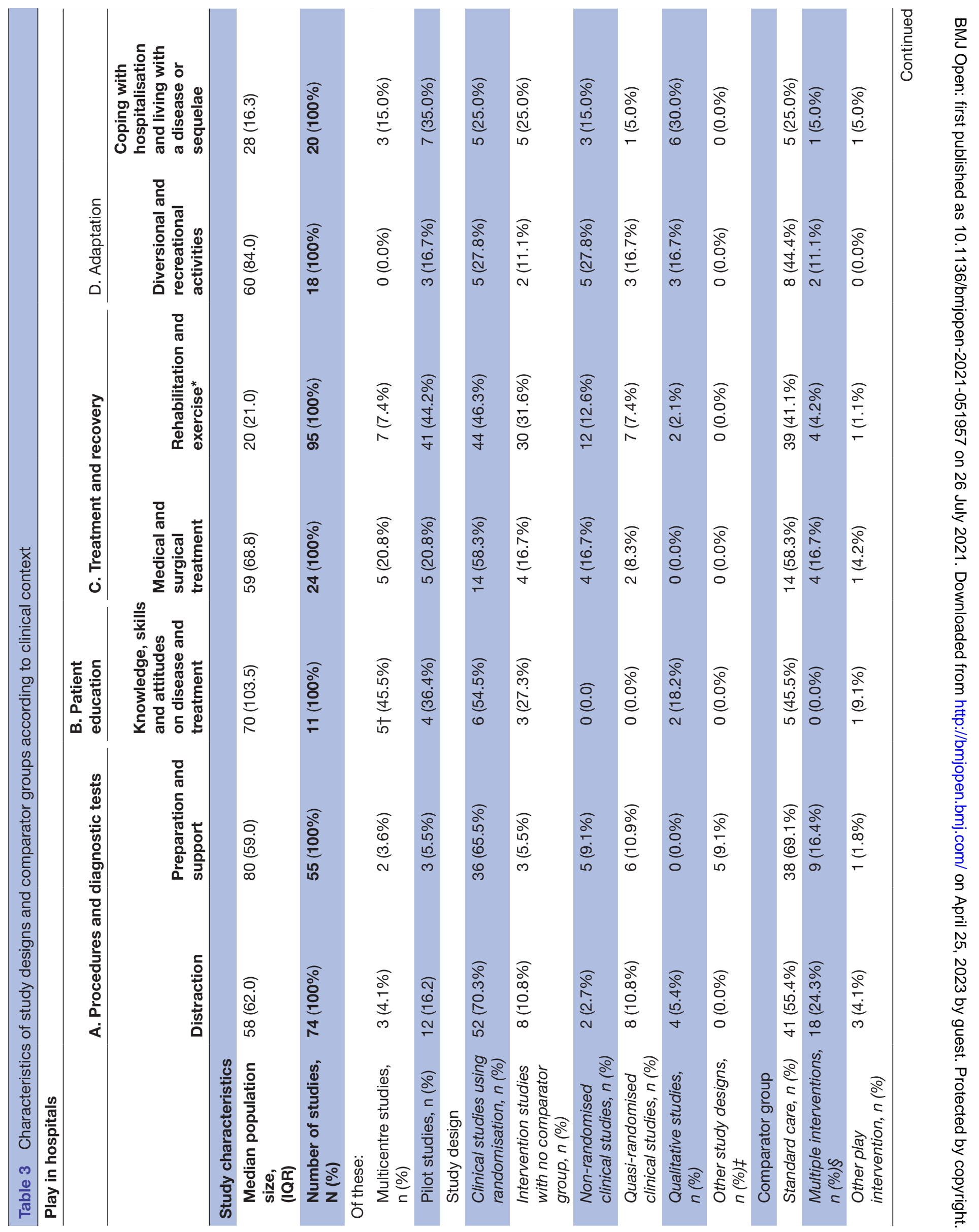




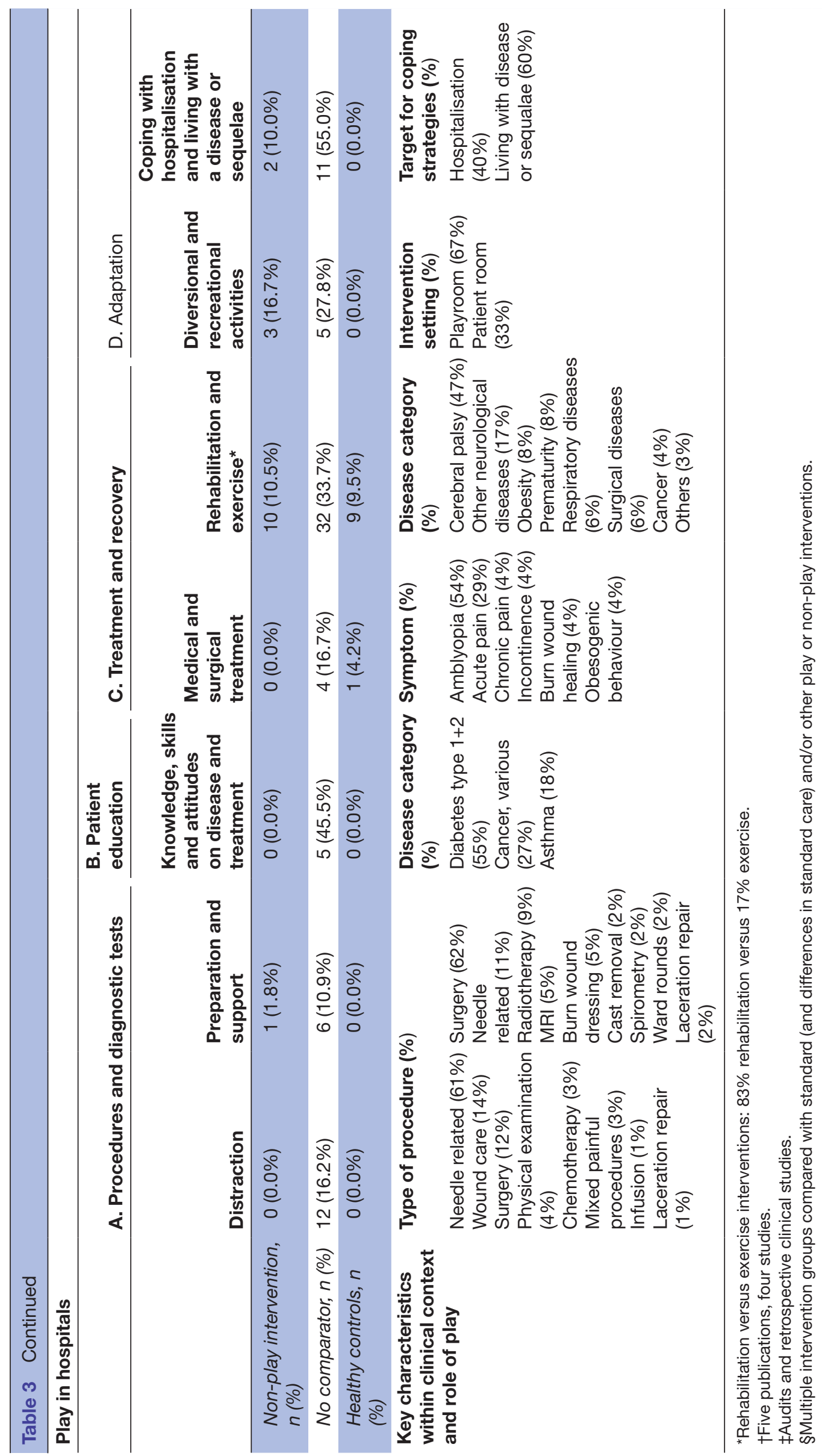


and to increase understanding and motivation; C) treatment and recovery, where play could supplement and occasionally replace conventional treatment and D) adaptation, where play provided space to express difficulties about being hospitalised and supported healthy childhood development.

Prior opinion papers and non-systematic reviews have suggested various subdivisions and definitions of play in hospitals, but not in a rigorous manner. ${ }^{2} 235859$ It is generally recognised that play interventions can be used in the preparatory phase and as a distraction during medical procedures, and that play has a normalising effect. $^{23} 58$ The term therapeutic play is used inconsistently to describe play with medical equipment, play in preparation programmes, ${ }^{17}$ and play therapy, similar to that used in child and adolescent psychiatry. ${ }^{22}$ Other subcategories, for example, directed play, non-directed play and supporting play have also been used unevenly. ${ }^{59}$ Our framework captures all of these subdivisions and contains a category for play as part of treatment and recovery, including rehabilitation. Previous reviews do not address this category, perhaps because rehabilitation and exercise are often outpatient activities and have only become a focus area more recently. ${ }^{60}$

Our framework may provide healthcare professionals and researchers with a tangible overview of the literature, while allowing play to retain its indefinable and ambiguous qualities. By summarising main characteristics, outcomes, general effects and potential pitfalls within the four clinical contexts, healthcare professionals and researchers are informed about play interventions similar to their own practices and research. Furthermore, this also informs about the breadth of possibilities and other approaches, which may encourage implementation of play interventions and inspire new ideas.

Our review primarily informs about facilitated and purpose-oriented play interventions in a clinical context. However, it is unknown whether this form of play positively impacts general health and development, which is a known benefit of unstructured play. ${ }^{8}$ Identifying solutions that allow play to serve as a preventative and generalpurpose activity in hospitals is crucial. Whether or not play interventions that support healthy childhood development in non-hospital environments are transferable directly to a hospital context is uncertain. Structural and cultural factors in hospitals challenge the opportunity for unstructured and free play, just as personal factors related to patients' illnesses and external factors such as an unfamiliar environment have an effect. ${ }^{6}$

Based on the current evidence, with very heterogenous and small studies, we were unable to draw conclusions on general aspects that could guide the implementation of future play interventions. Thus, additional high-quality research is needed to guide when, where, and what play to integrate into hospitals. Elaborating our proposed framework in a consensus-based study to further clarify principles for play interventions in hospitals, for example, the influence of age and development status on choice of play intervention, could serve to guide future research and play practices. ${ }^{2}$ Studies are warranted to assess shortterm and long-term effects of play integrated before, during and after procedures or treatments, and should address whether hospital play interventions can create an environment for children conducive to normal development. Importantly, input from paediatric patients will be central in informing concepts and future research in this regard. ${ }^{61}$

Furthermore, previous literature emphasised the significance of paediatric healthcare professionals who promote play, ${ }^{3}{ }^{62}$ but there is a lack of formal interprofessional training programmes available. ${ }^{63} 64$ Our review shows that treatment and care by various healthcare professionals may benefit from the incorporation of play interventions. This necessitates high-quality research evaluating the short, sustained and long-term effects of play interventions in hospitals to help overcome current barriers, such as lack of training among clinical staff. ${ }^{63}$

\section{Limitations}

Despite our broad definition of play, our literature search may have introduced selection bias and missed relevant articles. Moreover, we did not include grey literature or review references in included articles to find additional articles, and we only searched for published studies, which may have introduced publication bias. By restricting our inclusion to studies in English, we may have introduced additional selection bias, which may undermine the global generalisability of our findings, especially in terms of the lack of studies from low-income countries. Finally, we excluded literature from child and adolescent psychiatry, thus limiting the application of results to somatic aspects of the hospital system.

\section{CONCLUSIONS}

Hospital play interventions have a significant potential benefit for patient and family health, and both treatmentoriented and unstructured play activities need to be prioritised. Our developed four-part operational categorisation of hospital play interventions can serve as the first step in enabling stringency in the field as well as inspire further exploration, and thereby support for the needed professionalisation and academisation of the growing research interest in play in hospitals.

Acknowledgements We thank information specialists Librarian Tove M. Svendsen, Medical Library at Rigshospitalet, Copenhagen, Denmark and Librarian Anders Larsen, The University Hospitals Centre for Health Research, UCSF, Copenhagen University Hospital Rigshospitalet, Copenhagen, Denmark, who assisted in generating the strategy for the literature searches in different databases.

Contributors LKG conceptualised and designed the study, designed the data collection instruments, collected data, carried out the initial analyses and interpreted data, drafted the initial manuscript, and reviewed and revised the manuscript. JH and DD designed the data collection instruments, collected data, carried out the initial analyses and interpreted the data, and critically reviewed the manuscript for important intellectual content. MKT supervised data collection, analysed and interpreted the data, and critically reviewed the manuscript for important intellectual content. MAS conceptualised and designed the study, 
supervised data collection, interpreted the data and critically reviewed the manuscript for important intellectual content. EIG, JLG, PR, BO and TLF analysed and interpreted the data, and critically reviewed the manuscript for important intellectual content. JLS conceptualised and designed the study, coordinated and supervised data collection, interpreted the data and critically reviewed the manuscript for important intellectual content. All authors approved the final manuscript as submitted and agree to be accountable for all aspects of the work.

Funding The authors have not declared a specific grant for this research from any funding agency in the public, commercial or not-for-profit sectors.

Map disclaimer The depiction of boundaries on this map does not imply the expression of any opinion whatsoever on the part of BMJ (or any member of its group) concerning the legal status of any country, territory, jurisdiction or area or of its authorities. This map is provided without any warranty of any kind, either express or implied.

Competing interests The Centre for Research on Play in Education, Development \& Learning, Faculty of Education, University of Cambridge, Cambridge, UK is funded by the LEGO Foundation and a research grant from the National Institute for Health Research, UK.

Patient consent for publication Not required.

Ethics approval Not applicable as the review did not involve human or animal study subjects.

Provenance and peer review Not commissioned; externally peer reviewed.

Data availability statement All data relevant to the study are included in the article or uploaded as supplementary information.

Supplemental material This content has been supplied by the author(s). It has not been vetted by BMJ Publishing Group Limited (BMJ) and may not have been peer-reviewed. Any opinions or recommendations discussed are solely those of the author(s) and are not endorsed by BMJ. BMJ disclaims all liability and responsibility arising from any reliance placed on the content. Where the content includes any translated material, BMJ does not warrant the accuracy and reliability of the translations (including but not limited to local regulations, clinical guidelines, terminology, drug names and drug dosages), and is not responsible for any error and/or omissions arising from translation and adaptation or otherwise.

Open access This is an open access article distributed in accordance with the Creative Commons Attribution Non Commercial (CC BY-NC 4.0) license, which permits others to distribute, remix, adapt, build upon this work non-commercially, and license their derivative works on different terms, provided the original work is properly cited, appropriate credit is given, any changes made indicated, and the use is non-commercial. See: http://creativecommons.org/licenses/by-nc/4.0/.

\section{ORCID iD}

Line Klingen Gjærde http://orcid.org/0000-0001-6894-1024

\section{REFERENCES}

1 Richards SS, Wolff E. The organization and function of play activities in the set-up of a pediatric department: a report of a three-year experiment. Ment Hyg 1940;24:229-37.

2 Nijhof SL, Vinkers CH, van Geelen SM, et al. Healthy play, better coping: the importance of play for the development of children in health and disease. Neurosci Biobehav Rev 2018;95:421-9.

3 Yogman M, Garner A, Hutchinson J, et al. The power of play: a pediatric role in enhancing development in young children. Pediatrics 2018;142:e20182058.

4 American Academy of Pediatrics Committee on Communications, American Academy of Pediatrics Committee on Psychosocial Aspects of Child and Family Health. The importance of play in promoting healthy child development and maintaining strong parentchild bonds. Pediatrics 2007;119:182-91.

5 WHO Regional Office for Europe. Children's rights in hospital: Rapidassessment checklists. Copenhagen: World Health Organization, 2017.

6 Bolig R. Play in health care settings: a challenge for the 1990s. Child Health Care 1990;19:229-33.

7 Kleinberg S. Child life in the 1990s: changing roles, changing times. Child Health Care 1987;15:240-4.

8 Bolig R, Fernie DE, Klein EL. Unstructured play in hospital settings: an internal locus of control rationale. Child Health Care 1986;15:101-7.

9 Corlett S, Whitson A. Play and culture. Paediatr Nurs 1999;11:28-9.
10 Gates M, Hartling L, Shulhan-Kilroy J, et al. Digital technology distraction for acute pain in children: a meta-analysis. Pediatrics 2020;145:e20191139.

11 Charlier N, Zupancic N, Fieuws S, et al. Serious games for improving knowledge and self-management in young people with chronic conditions: a systematic review and meta-analysis. J Am Med Inform Assoc 2016;23:230-9.

12 Manyande A, Cyna AM, Yip P, et al. Non-pharmacological interventions for assisting the induction of anaesthesia in children. Cochrane Database Syst Rev 2015;7:CD006447.

13 McGuirt D. Alternatives to sedation and general anesthesia in pediatric magnetic resonance imaging: a literature review. Radiol Technol 2016;88:18-26.

14 Edwards AD, Arthurs OJ. Paediatric MRI under sedation: is it necessary? What is the evidence for the alternatives? Pediatr Radiol 2011;41:1353-64.

15 O'Connor M, Halkett GK. A systematic review of interventions to reduce psychological distress in pediatric patients receiving radiation therapy. Patient Educ Couns 2019;102:275-83.

16 Chow CHT, Van Lieshout RJ, Schmidt LA, et al. Systematic review: audiovisual interventions for reducing preoperative anxiety in children undergoing elective surgery. J Pediatr Psychol 2016;41:182-203.

$17 \mathrm{He} \mathrm{H-G}$, Zhu L, Chan SWC, et al. The effectiveness of therapeutic play intervention in reducing perioperative anxiety, negative behaviors, and postoperative pain in children undergoing elective surgery: a systematic review. Pain Manag Nurs 2015;16:425-39.

18 Drummond $D$, Monnier $D$, Tesnière $A$, et al. A systematic review of serious games in asthma education. Pediatr Allergy Immunol 2017;28:257-65.

19 Theng Y-L, Lee JWY, Patinadan PV, et al. The use of Videogames, Gamification, and virtual environments in the self-management of diabetes: a systematic review of evidence. Games Health J 2015;4:352-61.

20 Ravi DK, Kumar N, Singhi P. Effectiveness of virtual reality rehabilitation for children and adolescents with cerebral palsy: an updated evidence-based systematic review. Physiotherapy 2017;103:245-58.

21 Ravenek KE, Wolfe DL, Hitzig SL. A scoping review of video gaming in rehabilitation. Disabil Rehabil Assist Technol 2016;11:445-53.

22 Godino-láñez MJ, Martos-Cabrera MB, Suleiman-Martos N, et al. Play therapy as an intervention in hospitalized children: a systematic review. Healthcare 2020;8:239.

23 Koukourikos K, Tzeha L, Pantelidou P, et al. The importance of play during hospitalization of children. Mater Sociomed 2015;27:438-41.

24 Peters M, Godfrey C, Mclnerney P. Chapter 11: Scoping reviews, Joanna Briggs Institute reviewer manual. Adelaide, SA: The Joanna Briggs Institute, 2017.

25 Arksey H, O'Malley L. Scoping studies: towards a methodological framework. Int J Soc Res Methodol 2005;8:19-32.

26 McGowan J, Sampson M, Salzwedel DM, et al. PRESS Peer Review of Electronic Search Strategies: 2015 Guideline Statement. J Clin Epidemiol 2016;75:40-6.

27 Ouzzani M, Hammady H, Fedorowicz Z, et al. Rayyan-a web and mobile APP for systematic reviews. Syst Rev 2016;5:210.

28 Thomas J, Harden A. Methods for the thematic synthesis of qualitative research in systematic reviews. BMC Med Res Methodol 2008;8:45.

29 World Bank. Country classification, world bank country and lending groups: world bank, 2021. Available: https://datahelpdesk. worldbank.org/knowledgebase/articles/906519-world-bank-countryand-lending-groups

30 Tricco AC, Lillie E, Zarin W, et al. PRISMA extension for scoping reviews (PRISMA-ScR): checklist and explanation. Ann Intern Med 2018;169:467-73.

31 Moher D, Liberati A, Tetzlaff J, et al. Preferred reporting items for systematic reviews and meta-analyses: the PRISMA statement. PLoS Med 2009;6:e1000097.

32 Gerçeker Gülçin Ö, Binay Şeyda, Bilsin E, et al. Effects of virtual reality and external cold and vibration on pain in 7- to 12-yearold children during phlebotomy: a randomized controlled trial. $J$ Perianesth Nurs 2018;33:981-9.

33 Hedén L, VON Essen L, Ljungman G. Randomized interventions for needle procedures in children with cancer. Eur J Cancer Care 2009;18:358-63.

34 MacLaren JE, Cohen LL. A comparison of distraction strategies for venipuncture distress in children. J Pediatr Psychol 2005;30:387-96.

35 Ben-Pazi H, Cohen A, Kroyzer N, et al. Clown-care reduces pain in children with cerebral palsy undergoing recurrent botulinum toxin injections- a quasi-randomized controlled crossover study. PLoS One 2017;12:e0175028. 
36 Carlsson RNE, Henningsson RN. Visiting the operating theatre before surgery did not reduce the anxiety in children and their attendant parent. J Pediatr Nurs 2018;38:e24-9.

37 Nasir M, Ahmed MJ, Arshad RM. Play distraction versus pharmacological treatment to reduce anxiety levels in children undergoing day surgery. Medical Forum Monthly 2018;29:82-5.

38 Eijlers R, Dierckx B, Staals LM, et al. Virtual reality exposure before elective day care surgery to reduce anxiety and pain in children: a randomised controlled trial. Eur $J$ Anaesthesiol 2019;36:728-37.

39 Blanson Henkemans OA, Bierman BPB, Janssen J, et al. Using a robot to personalise health education for children with diabetes type 1: a pilot study. Patient Educ Couns 2013;92:174-81.

40 Pélicand J, Gagnayre R, Sandrin-Berthon B, et al. A therapeutic education programme for diabetic children: recreational, creative methods, and use of puppets. Patient Educ Couns 2006;60:152-63.

41 de Cássia Sparapani V, Liberatore RDR, Damião EBC, et al. Children with type 1 diabetes mellitus: self-management experiences in school. J Sch Health 2017;87:623-9.

42 Huss K, Winkelstein M, Nanda J, et al. Computer game for inner-city children does not improve asthma outcomes. J Pediatr Health Care 2003;17:72-8.

43 Shames RS, Sharek P, Mayer M, et al. Effectiveness of a multicomponent self-management program in at-risk, school-aged children with asthma. Ann Allergy Asthma Immunol 2004;92:611-8.

44 Shiri S, Feintuch U, Weiss N, et al. A virtual reality system combined with biofeedback for treating pediatric chronic headache--a pilot study. Pain Med 2013;14:621-7.

45 Adamo KB, Rutherford JA, Goldfield GS. Effects of interactive video game cycling on overweight and obese adolescent health. Appl Physiol Nutr Metab 2010;35:805-15.

46 Brütsch K, Koenig A, Zimmerli L, et al. Virtual reality for enhancement of robot-assisted gait training in children with central gait disorders. $J$ Rehabil Med 2011;43:493-9.

47 Del Corral T, Cebrià I Iranzo Maria Àngels, López-de-UraldeVillanueva I, et al. Effectiveness of a home-based active video game programme in young cystic fibrosis patients. Respiration 2018;95:87-97.

48 Parry I, Painting L, Bagley A, et al. A pilot prospective randomized control trial comparing exercises using Videogame therapy to standard physical therapy: 6 months follow-up. J Burn Care Res 2015;36:534-44.

49 Sajan JE, John JA, Grace P, et al. Wii-based interactive video games as a supplement to conventional therapy for rehabilitation of children with cerebral palsy: a pilot, randomized controlled trial. Dev Neurorehabil 2017;20:361-7.
50 Heutinck L, Jansen M, van den Elzen Y, et al. Virtual reality computer gaming with dynamic arm support in boys with Duchenne muscular dystrophy. J Neuromuscul Dis 2018;5:359-72.

51 Hung J-W, Chang Y-J, Chou C-X, et al. Developing a suite of Motion-Controlled games for upper extremity training in children with cerebral palsy: a proof-of-concept study. Games Health J 2018;7:327-34.

52 Gatica-Rojas V, Méndez-Rebolledo G, Guzman-Muñoz E, et al. Does Nintendo Wii balance board improve standing balance? A randomized controlled trial in children with cerebral palsy. Eur J Phys Rehabil Med 2017;53:535-44.

53 Potasz C, De Varela MJV, De Carvalho LC, et al. Effect of play activities on hospitalized children's stress: a randomized clinical trial. Scand J Occup Ther 2013;20:71-9.

54 Logan DE, Breazeal C, Goodwin MS, et al. Social robots for hospitalized children. Pediatrics 2019;144:e20181511.

55 Pinquart M, Skolaude D, Zaplinski K, et al. Do clown visits improve psychological and sense of physical well-being of hospitalized pediatric patients? A randomized-controlled trial. Klin Padiatr 2011;223:74-8

56 Hendon C, Bohon LM. Hospitalized children's mood differences during play and music therapy. Child Care Health Dev 2008;34:141-4.

57 Hinic K, Kowalski MO, Holtzman K, et al. The effect of a PET therapy and comparison intervention on anxiety in hospitalized children. $J$ Pediatr Nurs 2019;46:55-61.

58 Jun-Tai N. Play in hospital. Paediatr Child Health 2008;18:233-7.

59 Williams NA, Ben Brik A, Petkus JM. Importance of play for young children facing illness and hospitalization: rationale, opportunities, and a case study illustration. Early Child Development and Care 2019:1-10.

60 Committee on Hospital Care and Child Life Council. Child life services. Pediatrics 2014;133:e1471-8.

61 Howard J. The power of play. The Lancet 2020;395:261-2.

62 Milteer RM, Ginsburg KR, et al, Council On Communications And Media. The importance of play in promoting healthy child development and maintaining strong parent-child bond: focus on children in poverty. Pediatrics 2012;129:e204-13.

63 Stenman K, Christofferson J, Alderfer MA, et al. Integrating play in trauma-informed care: multidisciplinary pediatric healthcare provider perspectives. Psychol Serv 2019;16:7-15.

64 Jepsen SL, Haahr A, Eg M, et al. Coping with the unfamiliar: how do children cope with hospitalization in relation to acute and/or critical illness? A qualitative metasynthesis. J Child Health Care 2019;23:534-50. 